\title{
Measuring Intrinsic Traits of Children at Zoos
}

\author{
Alexandra M. Burris ${ }^{1 *}$ \\ 1 Toledo Zoo \& Aquarium; Indiana University-Bloomington, UNITED STATES \\ *Corresponding Author: alexandra.burris@toledozoo.org
}

Citation: Burris, A. M. (2021). Measuring intrinsic traits of children at zoos. Interdisciplinary Journal of Environmental and Science Education, 17(4), e2246. https://doi.org/10.21601/ijese/10939

ARTICLE INFO ABSTRACT

Received: Zoos are in a unique position to affect the development of youth in ways that are consistent with 21 September 2020 cultivating pro-environmental behaviors. The purpose of this study was to examine three intrinsic traits of youth important to the goals of conservation education: prior knowledge about animals,

Accepted: interest in animals, and value for animals. The framework of this study is the conceptual model of learning that posits that any changes that occur during a single visit to an informal learning institution 10 February 2021 (such as a zoo) will be affected and informed by the intrinsic traits of the individual and various external factors. This study explored three intrinsic traits predicted to be important for informal learning. The research design followed a constructivist design meant to capture measurements of prior knowledge, interest, and value from the participants' own perspectives. This study describes these three traits in a sample of 37 youth between the ages of 7 and 14, largely zoo members, attending the zoo with their parents. In particular, I describe unique methods of measuring these three traits including a drawing activity meant to assess the children's construction of knowledge about animals, and questionnaires meant to assess the youth's interest and value. The data analysis in this paper provides descriptions of the three traits as they are constructed among the youth participants in order to inform future correlations between intrinsic traits and in-zoo behavior. The results of the study indicated that youth organize their knowledge about animals around ecological and morphological concepts and that this forms the basis for their interest in and value for animals.

Keywords: zoos, informal education, free-choice education, intrinsic traits, conceptual model of learning, constructivist

\section{INTRODUCTION}

Free-choice learning is the term that describes experiences where the learner exercises almost complete control and choice over what and where they are learning (Falk, 2006). As such, one of the most important units of study in research on freechoice learning is that of the individual as they interact within their immediate social group (Christidou, 2013; Crowley at al., 2000; Geerdts, Van de Walle, \& LoBue, 2015; Palmquist \& Crowley, 2007). As a subset of free-choice learning institutions, free-choice wildlife education settings such as zoos and aquariums are unique in their capacity to provide up-close encounters with animals. Most zoos and aquariums contain as some part of their mission to foster awareness and connections with animals in the hopes that these connections will result in visitors taking positive environmental action to help conserve wildlife (Falk, Heimlich, \& Foutz, 2009).

The purpose of this study is to explore and describe the traits of youth zoo visitors. In this paper I use the term intrinsic traits along constructivist ideas meaning qualities that the participants actively build and construct based on their experiences and reflection upon those experiences. The goal of the paper is to explore new methods of measuring traits and explore the wide spectrum of how traits in this particular population manifest. In particular, this paper will explore three traits found among youth visitors to a zoo: knowledge about animals, interest

Copyright (C) 2021 by Author/s and Licensed by Veritas Publications Ltd., UK. This is an open access article distributed under the Creative Commons Attribution License which permits unrestricted use, distribution, and reproduction in any medium, provided the original work is properly cited. 
in animals, and value for the environment. These three traits align with the goals of zoos and aquariums and are of interest for researchers in this field to explore. In particular, the traits developed among youth (between 7-14 years old) are of interest because these traits may continue to inform their behavior as adults.

The research question explored in this study is: What are the states of the traits of knowledge, interest, and value as constructed by a sample of youth zoo visitors and how do these three traits relate to each other? In the following section I briefly review literature about these three traits to inform their measurement.

\section{Literature Review}

Overall I take a constructivist and developmental view of interest, knowledge, and value. Multiple studies show that children follow predictable patterns of development in these three constructs as influenced by an individuals' social, physical, and cultural environment.

\section{Knowledge}

Contemporary free-choice education theorists define learning as an experience or by constructing one's own meanings (Allen, 2002; Ash, 2003; Perry, 2012) This requires unique forms of measurement such as when Jenson (2013) measured how children construct knowledge by having them draw pictures of animals to show what children learned about adaptations and proper habitats for animals.

Recent empirical studies explore learning by examining dialogue that occurs during visits to informal learning institutions. For example, Allen (2002) and Ash (2003) both used coding schemes of dialogue as evidence of learning such as talk about science content (namely animal adaptations) and the use of science process skills. Barriault \& Pearson (2010) equate learning to the level of engagement a visitor has in an exhibit (initiation, transition, and breakthrough). More specific to zoos and animals, Kimble (2014) suggested that the extent to which visitors discussed biodiversity is evidence that children were learning about aspects of biodiversity at these three settings. Similarly, Kisiel, Rowe, Vartabedian \& Kopczak (2012) provided qualitative evidence for learning activities at touch tanks in aquariums. Common activities of the families such as listening to staff, naming, scanning, making claims, challenging claims, seeking information, seeking evidence, and testing claims were interpreted as forms of learning. Taken together these studies provide evidence that learning should be measured in relationship to prior experiences and personal connections.

\section{Interest}

Affective domains such as interest are less studied but are equally as important to the goals of freechoice institutions, especially those with goals of increasing concern for animals. Research suggests that interest develops along a predictable continuum. Hidi and Renninger's (2006) four-phase model of interest provides a conceptual framework for understanding the development of interest by categorizing people along a continuum of interest. In their model, interest starts with the triggering of situational interest which leads to repeated engagement. At the other end of the continuum, a well-developed individual interest is defined by high levels of engagement and high intrinsic motivation for participation in the subject of interest (Hidi \& Renninger, 2006).

Studies regarding the development of interest in free-choice settings are primarily focused on early stages of interest such as exhibits that do or do not trigger interest (e.g. Moss \& Esson, 2010). In fact, most research studies purporting to examine interest in wildlife education centers use a very simple measure-dwell time (the amount of time a visitor spends at a certain exhibit component) as a their definition of "interest" (Johnston, 1998; Moss \& Esson, 2010). This shows that interest has not been a focus of study for free-choice wildlife education institutions and contemporary measurement should account for varying stages of interest development.

\section{Value}

Value is a difficult trait to measure with a variety of definitions in the literature. Some studies group people into categories depending on their beliefs. For example, Kellert \& Berry (1987) proposed different types of attitudes towards animals such as naturalistic (interest and affection for wildlife), ecologistic (primary concern for the environment as a system), and humanistic (primary interest for individual animals such as pets). Skibins \& Powell (2013) define "conservation caring" as a trait consisting of awareness of consequences of human action as well as ascription of responsibility.

Values also follow developmental trajectories among children. In particular, children moved along a trajectory from egocentrism in focusing on animal appearance and what they enjoy about animals to demonstrating empathetic perspective taking and concern for endangered animals around 8-12 years old (Kidd \& Kidd, 1996). Myers et al. (2004) found that values developed in relatively predictable ways as children move from anthropomorphic conceptions of animals (such as animals needing to live in a house) to more complex understanding of the ecological needs of animals. 


\section{Summary}

Knowledge, interest, and value are not only influenced by development over time by contextual factors; they also mold and shape each other. Despite subtle differences in each of these three traits, empirical and theoretical work supports that values, interest, and knowledge are interrelated (Hidi \& Renninger, 2006; Uitto \& Saloranta, 2010). For example, interest may preclude knowledge-seeking activities and result in more value for the object of interest (Hidi \& Renninger, 2006) while valuerelated orientations may affect engagement and interest in certain issues or activities (Uitto \& Saloranta, 2010).

\section{THEORETICAL FRAMEWORK}

The theoretical framework for this study is the conceptual model of learning proposed by Falk \& Dierking (2013) where the authors posit that learning is influenced by the personal, physical, and sociocultural context over time. Using this model, I follow the assumption in this paper that the intrinsic traits of youth will be influenced by their external circumstances. The conceptual model of learning is related to constructivist views of education that take into account for how individuals create their own knowledge through their interaction with the world and prior life experiences. In other words, the conceptual model of learning takes a constructivist view of the individual such that any measurement of learning cannot be separated from the life experiences of the individual. This paper extends this view to encompass other intrinsic traits that develop over time including interest and value. The three traits chosen to study in this paper are important to practitioners of environmental education. As such, measurement of these traits will provide insights into how interventions such as a zoo visit might improve the positive outcomes of their mission such as increasing knowledge or value for nature and animals. Describing constructivist methods for measuring these traits has practical implications for the design of experiential learning opportunities at informal education institutions.

\section{METHODS}

\section{Recruitment and Study Sample}

This paper uses a descriptive design to explore the answer to the question of what are the states of knowledge, interest, and value in youth zoo visitors. The research methods used self-reported surveys which allowed participants to demonstrate their own construction of the traits measured in the study. The surveys were adaptations of previously used instruments as described below. This study was part of a larger study seeking to correlate measurements of the three traits with actions and dialogue during the visit; however, the focus of this paper is only on descriptive measurements of the three traits.

$\mathrm{I}$, as the single researcher, approached families at the entrance to the zoo on Saturdays and Sundays in January and February. Qualitative and quantitative surveys were distributed to youth participants as they entered the zoo. Youth participants were given surveys before entering the zoo and then asked to wear a point-of-view camera during the duration of their visit. The families were intercepted at the end of the visit and given a second survey. Focus of this paper is on descriptive analysis of the surveys however a brief discussion of the video data is included for triangulation of the descriptive analysis. Correlational analysis between the survey data and video data will be explored in future studies.

Thirty-seven children and their families were included in the final analysis. Of these, 19 children were male and 18 were female. The youngest child was 7 years old and the oldest was 14 with an average age of 10 . Twenty-three of the families (62\%) held memberships and 14 did not (38\%). The number of times the families visited zoos in the past year is divided out in Table 1 . The table reveals that the participants of the study were frequent visitors to zoos with over a fourth of the families visiting over 10 times in the past year. Non-members had lower numbers for their visitation, generally visiting between 0 to 2 times in the past year.

The group was skewed toward members and frequent visitors. However, this may be because data was collected during winter months when overall visitation is lower. The following section will describe in more detail the surveys used to collect data from participants.

\section{Data Sources}

In order to examine children's intrinsic traits and the ways they manifest during a zoo visit, I used three methods for collecting data. First, I collected data before the children entered the zoo via a drawing task

Table 1. Number of visits to zoos in the prior 12 months among the families involved in the study $(\mathrm{N}=37)$

\begin{tabular}{cc}
\hline $\begin{array}{c}\text { Number of zoo } \\
\text { visits in prior } \\
12 \text { months }\end{array}$ & Number of families \\
\hline $0-1$ & 8 \\
\hline $2-3$ & 9 \\
$4-5$ & 4 \\
$6-9$ & 6 \\
$10+$ & 10 \\
\hline
\end{tabular}


and questionnaire to measure knowledge. The second piece of data came from observations utilizing point-of-view cameras throughout the child's visit. After the visit, children took a second survey to assess their interest and value toward animals. The intent of having components before and after the visit was not to assess any change in knowledge. According to the conceptual model of learning, changes in knowledge take place over time and a single visit is unlikely to result in considerable changes to intrinsic traits of children. Instead, the results of these surveys reflect a snap-shot in time that were influenced by prior experiences and will change with future events. Therefore, the reason for using surveys before and after the visit were simply to spread out the surveys so that less time would need to be spent by participants upon entering and leaving the zoo. The participants may not answer thoroughly if they felt rushed based on time constraints.

\section{Drawing Activity and Pre-Questionnaire}

The pre-questionnaire utilized components of a few different vetted instruments from prior studies. The underlying structure of the knowledge assessment followed the structure of personal meaning mapping (Falk et al., 1998), a widely used method of exploring the development of conceptions in free-choice settings where the visitors' thoughts form the basis for an open-ended interview where they explain and expand on their ideas (Falk et al., 1998).

A version of this method has been used in prior research to explore children's conceptions about animals by asking them to draw an animal (Jensen, 2013; Kimble, 2014; Myers et al., 2004; Wagoner \& Jensen, 2010). In each of these studies, the method was used successfully as a measure of knowledge about animals and coded with high reliability.

For the drawing activity in this study, I asked participants to draw their favorite animal and report everything they know about that animal. Myers et al. (2004) asserts that development of knowledge about animals may be closely tied to the child's favorite animal, and for this study, it was not imperative to understand the child's knowledge about all animals but rather to give them the "best chance" to demonstrate their knowledge. If children struggled to come up with any facts, I gave them three verbal prompts: What does it eat? What does it do? Where does it live? I noted if these prompts were used.

The pre-survey also included a few items to measure interest and value toward their favorite animal. These questions asked them to rank how much they agreed with the following statements: "this animal is important," "I would be sad if this animal went extinct," and "I want to learn everything
I can about this animal." The children also responded to the open-ended question, "Why is this animal important or not important?"

\section{Post-Questionnaire}

I adopted the measure of interest from the "fascination in science" measure by Chung, Cannady, Schunn, Dorph, \& Bathgate (2016). The authors describe the trait of fascination as involving interest and positive affect toward science that serves as a driver for participation. I used the instrument in its entirety but substituted the term "animal" any time the term "science" was used. The instrument was written for 10-14 year-old respondents corresponding with the ages of the children in my study; however younger participants were readaloud the survey by either parents or myself. Chung et al. (2016), assert that the construct is malleable but not expected to change over interventions of very short duration, so the instrument should provide an accurate measure of current levels of fascination at the time of the study. The items on the instrument were a series of multiple choice questions with four choices asking the youth to choose the word that best fit their agreement with the question.

Value toward animals was measured using an instrument adapted from Skibins et al. (2013) meant to measure the construct of "conservation caring" defined as visitors' connection to a species and found to be a predictor for pro-conservation activities. Because the items were meant to be administered to adults, the wording of the items was adjusted slightly to use more simple vocabulary and the choices for each item were taken from the fascination index (Chung et al., 2016) for consistency in the survey. Additionally the questions were worded more broadly to encompass animals in general instead of a single species.

\section{Data Analysis}

The questionnaire contained both qualitative and quantitative measures of the three main constructs: knowledge, interest, and value. Analyses of these three dimensions are discussed separately.

Knowledge. I coded the drawings in a manner similar to Personal Meaning Mapping, a widely used tool in free-choice education (Falk et al., 1998). The following dimensions were used:

-Dimension One: Total quantity of relevant vocabulary used.

-Dimension Two: Breadth of understanding. The number of different categories of knowledge used by the child. Categories were adapted from Myers et al. (2004), with a few additions that emerged during analysis. The categories will be explored in the results section. 
-Dimension Three: Depth of understanding. Detail and complexity of descriptions of each category. Vocabulary divided by categories.

-Dimension Four: Mastery. Rankings of whether items are "correct" versus "incorrect." This dimension was ranked using a four-point rubric. The rubric is included in Table 2 .

Since the scores and categories were derived from the children's responses, they do not represent an objective measure of knowledge but rather the children's construction of ideas related to their favorite animal. Consistent with Falk et al. (1998), I added the sub-scores on the four dimensions to provide a composite score for "knowledge" of the child and then used this to divide the children into three knowledge groups: high, medium, and low knowledge based on their relation to the median score. Since the composite knowledge score had no upper limit, grouping the youth in this way allows for comparisons among youth without the effects of upper outliers.

Interest. Scores for interest were obtained using an average of scores on the fascination index consistent with Chung et al. (2016). Responses to the multiple-choice questions were transformed to numerical values with the lowest agreement response (NO!) scored as "1" and the highest agreement level (YES!) scored as "4" I chose to use a simple average because concern was merely about relative amounts of the construct of interest rather than absolute scores. In reviewing the Cronbach's alpha for the mean score, the value was .83, which aligned with the scores found by Chung et al. (2016), and a scree plot indicated the scores were unidimensional, providing support for the use of the mean.

Parents were asked to rank their child's interest in animals and in a career involving animals from 1-7. The child participants indicated what they would like to be when they grow up and these answers were coded into categories for animal science, non-animal
STEM, non-STEM, and no idea. All these measures were used to approximate interest from different angles.

Value. I averaged the results from the six survey questions adapted from Skibins et al. (2013) using the same method as the mean interest score (described above). Cronbach's alpha for the items was .83 and again the scree plot indicated a single dominant factor.

Value was also triangulated from a few other sources of data. I coded responses to the open-ended question regarding why animals are important in line with the categories of values towards animals proposed by Kellert and Berry (1987). These categories are still currently used in research on values. Two categories of values emerged in analyzing the data: uncommon (valuing an animal because it is rare or endangered), and experience (valuing an animal because of personal experience with the animal). The categories will be explored in the results section.

\section{RESULTS}

In this section I first examine the constructs separately, discussing descriptive statistics for each variable and providing descriptions and examples of the categories used. After this, I discuss how the video data provides triangulation for the three constructs.

\section{Knowledge}

Regarding the number of relevant vocabulary used by youth in the drawing activity, the count ranged from one to 15 . The average number of vocabulary terms used by youth in their interview was four. The vocabulary score of 15 was an outlier from a particularly talkative participant, Jack. The next highest vocabulary score was seven.

The categories used to assess breadth of vocabulary come directly from Myers et al. (2004). One category was added to the framework that emerged in this study — "trait/adaptation." When

Table 2. Rubric for mastery dimension of knowledge assessment

\begin{tabular}{cl}
\hline Score & Criteria \\
\hline 1 & $\begin{array}{l}\text { Mostly incorrect information OR only very simple information not specific to that animal (i.e. it needs food } \\
\text { and water) }\end{array}$
\end{tabular}

2 Mostly correct information but may have some incorrect still. Some vocabulary that is specific to the animal but usually simple or well-known terms.

3 Correct information with only slight inaccuracies (such as using the word poisonous instead of venomous). Includes 2-3 specific facts about the animal but generally these are fairly "well known facts" such as "pandas eat bamboo" ... [having to be prompted extensively for more facts may keep from getting to level four]

$4 \quad$ All information is correct and accurate. Includes 1 or more unusual or less well-known facts among their 2 3 other facts. 
Table 3. Number of responses to breadth categories of knowledge $(n=37)$

\begin{tabular}{|c|c|c|c|}
\hline Response Category & $\begin{array}{l}\text { Number of } \\
\text { Responses }\end{array}$ & Definition & Examples \\
\hline Ecological & 25 & $\begin{array}{l}\text { Ecological needs of animals including } \\
\text { specific habitat, predators/prey, etc. }\end{array}$ & $\begin{array}{l}\text { "They catch flying birds and turkeys' } \\
\text { (John, 9, caracal) }\end{array}$ \\
\hline Trait/Adaptation & 20 & $\begin{array}{l}\text { Feature of animals such as color, pattern, or } \\
\text { adaptations like horn/antlers }\end{array}$ & $\begin{array}{l}\text { "You can see through the glass frog'؛ } \\
\text { heart and see the lungs moving' } \\
\text { (Sayid, } 10 \text {, glass frog) }\end{array}$ \\
\hline Activity/Behavior & 13 & Things animals do like bathing/jumping & $\begin{array}{l}\text { "They bathe themselves witl } \\
\text { dust/dirt" (Shannon, 13, elephant) }\end{array}$ \\
\hline Physiology & 13 & Simple needs of animals: food, water, shelter & “They drink water” (Nikki, 7, lion) \\
\hline Taxonomy & 11 & Specific species names, taxonomic group & $\begin{array}{l}\text { "They are part of the cat family" } \\
\text { (Danielle, } 12 \text {, tiger) }\end{array}$ \\
\hline Psychological & 8 & Feelings or emotional states of animals & $\begin{array}{l}\text { "They can cheer you up" (Sawyer } \\
\text { 13, chicken) }\end{array}$ \\
\hline Reproductive & 2 & Breeding or mating facts & $\begin{array}{l}\text { "Seahorses give birth to } 1000 \text { babies } \\
\text { at once" (Ana Lucia, 9, sea horse) }\end{array}$ \\
\hline
\end{tabular}

asked to name everything they knew about their favorite animal, many children named traits of animals such as their color, pattern, or features necessitating this new category. Table 3 outlines the categories used to determine breadth score in this study as well as the number of responses in each of these categories. Youth mentioned more than one category during the interview so youth may be included in multiple categories.

In examining the number of youth who mentioned each category, the most common types of vocabulary used were ecological and trait/adaptation (Table 3). Examples of the different categories are included in Table 3. Depth was calculated by dividing total vocabulary by the number of categories used. The average score for depth was 1.7. On average youth mentioned around two vocabulary terms per category.

Finally, I scored the drawings using a rubric for mastery that took into account the correctness of the youth's statements as well as the relative complexity of the facts they provided. Exploring the types of facts along this continuum provides a different lens for examining the type of knowledge youth hold about their favorite animal. For example, Bernard (9) received a high rating for mastery by including this fact about snow leopards, "When they breathe through their nose, air warms up before it hits their lungs." Illana (7) had a lower score in mastery by saying about bears "they eat meat and they live in cold places." Mastery was scored from 1 to 4 and the spread of scores was roughly normally distributed across youth. The average score for mastery was 2.4. Ten youth $(27 \%)$ received a score of 1 , ten $(27 \%)$ a score of 2 , eleven $(30 \%)$ a score of 3 , and six (16\%) received the highest score of 4 . Using Pearson correlations, mastery score had a moderate correlation with age $r(35)=.33, p=.04$. Not surprisingly older youth scored higher in mastery than younger youth. There were gender differences in mastery but this was not significant. The average mastery score for boys was 2.7 and for girls 2.0.

I calculated the composite score for knowledge by adding the sub-scores for each of the four areas (vocabulary, breadth, depth, mastery). The composite score is a continuous variable with no upper limit since the amount of vocabulary depended on the participant. The average composite knowledge score was $10.40(S D=4.21)$. Scores ranged from a minimum score of 3 to a maximum score of 26.75 . The maximum score of 26.75 from Jack was deemed an outlier beyond 3 standard deviations from the mean. Using Pearson correlations, the composite scores did not correlate with age. There were gender differences, but these differences were not significantly significant. The average composite score for boys was 11.4 and for girls 9.1.

Finally, I ranked the youth as low, medium, or high knowledge based on the relationship of the individuals score to the mean. I decided to do this because the composite score can be misleading since the score has no upper limit. Thus, youth with 
extremely high composite knowledge scores could skew results and using these categories allowed for comparisons without this effect. Eleven participants were labeled as "high" knowledge, 16 were labeled as "medium" knowledge, and 10 were labeled as "low" knowledge. Some examples of the youth's pictures within these three categories are illustrated in Figure 1 to provide better insight into youth's construction of knowledge about their favorite animals.

\section{Interest}

Interest was measured using the fascination index on the survey. Youth's mean interest ranged from 2 ("no") to 4 ("YES") based on their agreement with the statements on the survey. The average for the index in the sample in this study is $3.3(\mathrm{SD}=0.55)$. The scores were roughly normally distributed.

Parents also responded to a single item on a 7point Likert-type scale that asked them to rate how interested they believed their child was in a career involving animals. The mean interest score from the fascination index correlated positively with the parents' responses to the item regarding their child's interest in pursuing a career in animals $r(34)=.68$, $p=.001$.

I coded the children's reported career choices as animal science, non-animal STEM, or non-STEM. Seventeen youth (46\%) wanted to be an animal scientist of some sort (i.e. zookeeper, vet, zoologist), seven (19\%) wanted a non-animal STEM career (i.e. doctor, geologist, etc.), and 10 youth (27\%) wanted a career outside of STEM (i.e. journalist, graphic design, etc.). The rest had no idea or did not answer (8\%).

An ANOVA confirmed significant differences among the three groups as categorized by career interest, $F(2,34)=14.7, p<.01$. In pairwise comparisons, participants who said they wanted to be in animal science $(M=3.7)$ had higher mean interest compared those who wanted a non-animal STEM career $(M=3.2, \mathrm{p}=.015)$, and those who wanted a non-science career $(M=2.9, \mathrm{p}<.01)$ as illustrated in Figure 2. There was not a significant difference between the non-animal STEM and nonSTEM groups.

The higher mean interest score among the animal science group provides triangulation for the fascination index as a measure of interest since theory suggests those who with a higher interest in something are more likely to want to pursue a career in that subject in the future (Lent et al., 1994).

\section{Value}

Value was assessed with the survey in a similar manner to interest. Mean value scores of individuals ranged from 1.5 to 4.0 with a mean of $3.65(\mathrm{SD}=0.47)$ and the data was left skewed. There were four outliers representing the few children who had very low value scores while the rest of the scores were clustered at the high end. These outliers were kept in all analyses because it was of interest to see if these individuals acted differently from the other participants. I asked youth "why is this animal important" regarding their favorite animal. Responses to this question were coded using the framework from Kellert \& Berry (1987) to classify the youth into "value-type" categories. These categories are outlined in Table 4 along with the frequency that youth's responses fell into each of the categories. Youth only fell into one category based on their response. As shown in Table 4, the most common value code was ecologistic (13 youth= $36 \%)$. Examples are included in Table 4. The second most common was the emergent code uncommon defined by youth that found value in animals because of their endangered or uncommon status Only one participant reported a negativistic view-Nikki (7) who thought lions are not important “because I don't really like them." There were no differences in the categorization of respondents by age or gender. In pairwise comparisons with Bonferroni correction, youth combined together with ecologistic and scientific category had significantly higher mean value scores $(\mathrm{M}=3.7)$ compared to youth categorized in the utilitarian or negativistic category $(M=3.0)$, $p=.04$.

\section{Relationship between Traits}

Based on prior research, I predicted that the three variables examined in this study would be related since many models include knowledge and interest as precursors to environmental values (Bamberg \& Moser, 2007). I compared the scores for each of the three traits using Pearson correlations and beta regression.

Child composite knowledge scores and knowledge groupings did not correlate with either of the other two child-reported constructs (mean interest and mean value). However the child's composite knowledge score correlated with the parent's rating of their child's interest in a career in animals $r(35)=$ .33, $p=.047$. Mean interest and mean value had some relationship using a Pearson correlation $r(35)=.68$, $p<.001$. Those with higher average interest also had higher average value.

Finally, I grouped participants based on whether they were high or low in each of the traits with respect to the median score for each trait. Those with scores above the median labeled as high and those below the median as low. This simple categorization resulted in seven groups. The number of participants falling into each group is outlined in Table 5 . The group with low knowledge and high interest/value 
was the most common group with $32 \%$ of participants in this group followed by group where youth were high in all three traits (16\%).

A univariate linear regression model was conducted with youth's age as the outcome variable and the categories from Table 5 as the independent variables. Using an ANOVA comparing among these groups, there was a significant main effect for age, $F(6,29)=3.0, p=.02$. In particular in pairwise comparisons with Bonferroni correction, youth in the LHH group ( $M=8.7, p=.003)$ and LLH group $(M=9.3)$, were significantly younger than the other groups, $p=.03$. There were no differences based on gender.

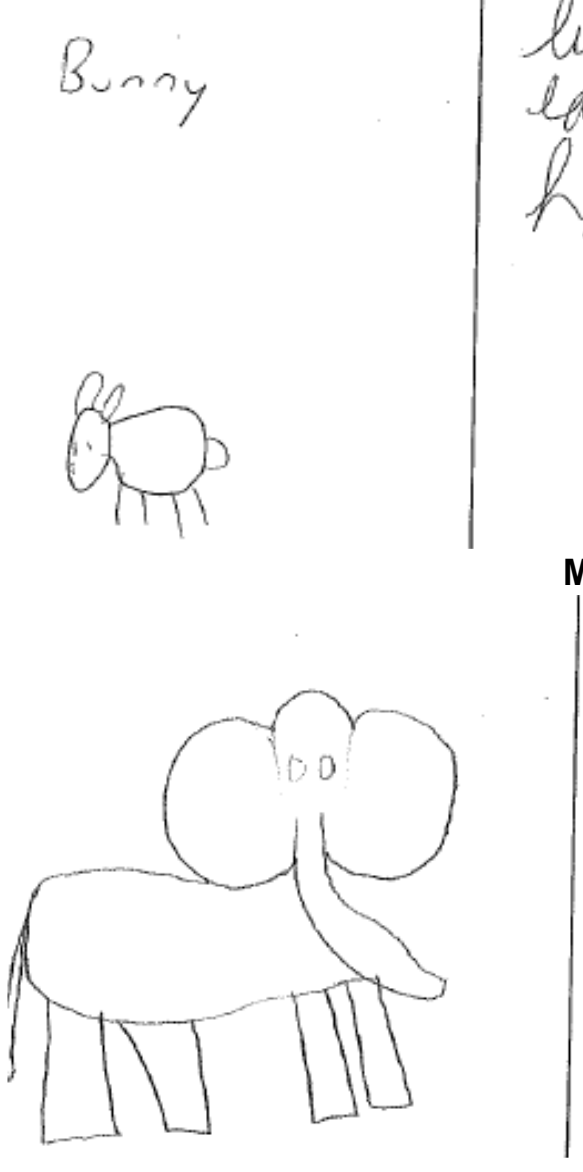

LOW:
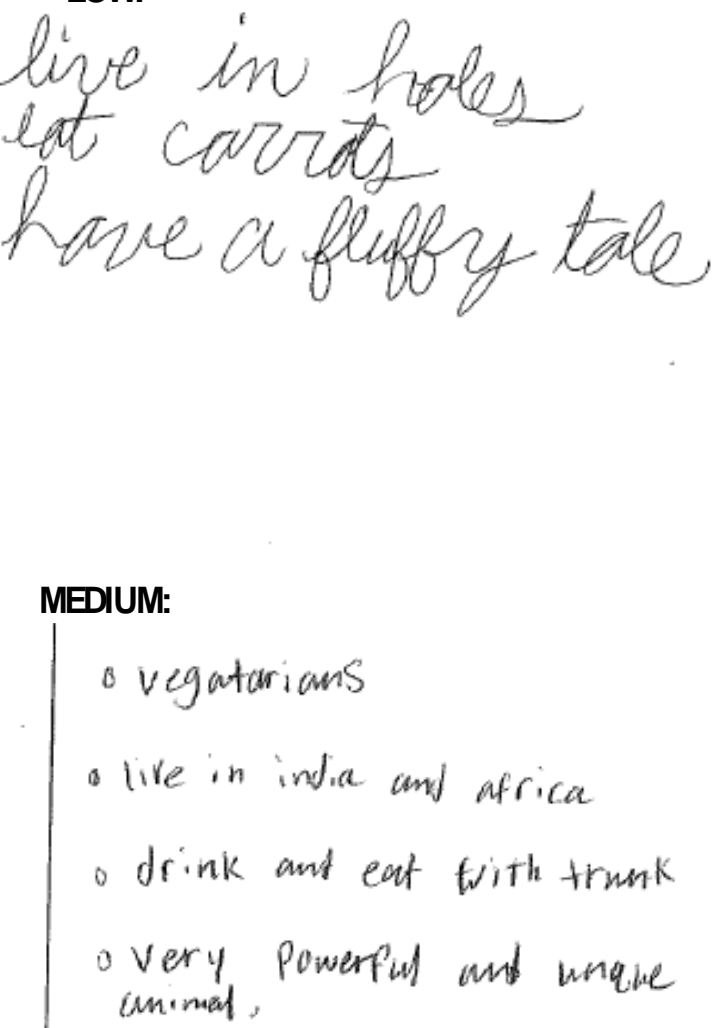

HIGH:

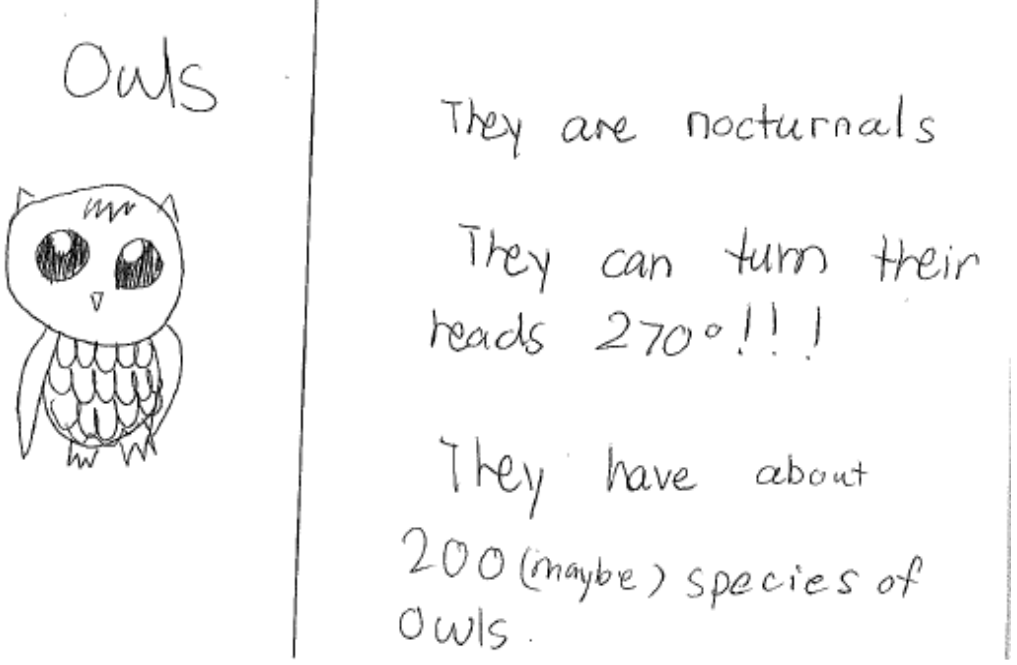

Figure 1. Examples of drawing activity, the first receiving a "low" score, the second receiving a "middle" score, and the last receiving a "high" score 


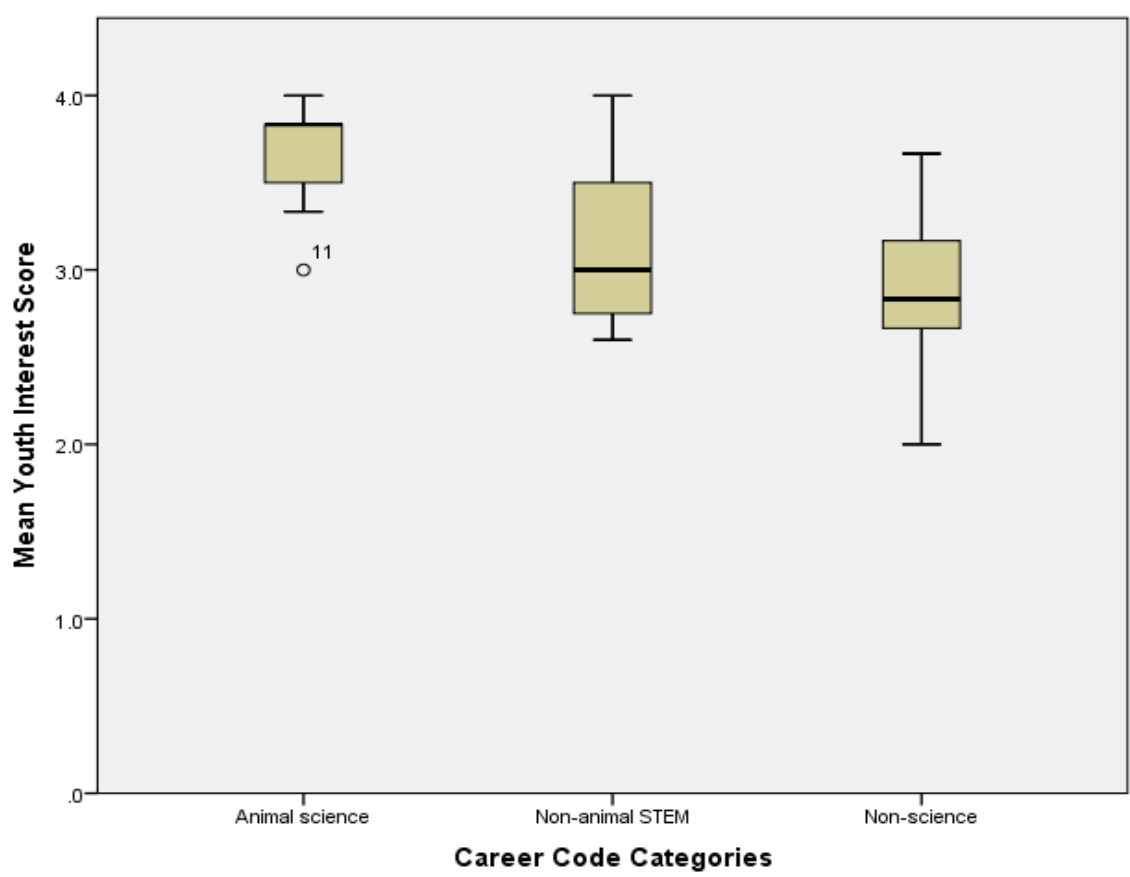

Figure 2. Mean interest scores for participants among three codes used to describe their career choice, Animal science $(n=17)$, non-animal STEM $(n=7)$, and non-science $(n=10)$

Table 4. Number of respondents in value categories $(n=37)$

\begin{tabular}{|c|c|c|c|}
\hline Response Category & $\begin{array}{c}\text { Number of } \\
\text { Respondents }\end{array}$ & $\begin{array}{l}\text { Animal } \\
\text { Important/Not } \\
\text { Important }\end{array}$ & Examples \\
\hline Ecologistic & 13 & $\begin{array}{l}\text {...because of role in } \\
\text { ecosystem }\end{array}$ & $\begin{array}{l}\text { "... because all animals play a vital } \\
\text { role in ecosystems" (Kate, 12, } \\
\text { turtle) }\end{array}$ \\
\hline Uncommon & 6 & $\begin{array}{l}\text {...because it is } \\
\text { endangered/rare }\end{array}$ & $\begin{array}{l}\text { "... because they are endangered" } \\
(\text { Ethan, } 9)\end{array}$ \\
\hline Naturalistic & 4 & ...just because I like it & $\begin{array}{l}\text { "because I just really love them" } \\
\text { (Penny, 9, hippo) }\end{array}$ \\
\hline Aesthetic & 3 & ...because of how it looks & $\begin{array}{l}\text { "because he is cute" (Rose, } \\
\text { armadillo) }\end{array}$ \\
\hline Utilitarian & 3 & ...because I use them & $\begin{array}{l}\text { "for their eggs and meat" (Sawyer, } \\
13 \text {, chicken) }\end{array}$ \\
\hline Moralistic & 2 & $\begin{array}{l}\text {...because animals are } \\
\text { living too }\end{array}$ & $\begin{array}{l}\text { "Animals are living things too" } \\
\text { (Sun, 10, owl) }\end{array}$ \\
\hline Other & 2 & ...other reasons & $\begin{array}{l}\text { "Because my mom likes them" } \\
\text { (Libby, } 8 \text {, horse) }\end{array}$ \\
\hline Scientific & 2 & $\begin{array}{l}\text {...because of its unique } \\
\text { traits }\end{array}$ & $\begin{array}{l}\text { "Because it can jump } 4 \text { feet higher } \\
\text { than a kangaroo" (John, 9, caracal) }\end{array}$ \\
\hline Negativistic & 1 & ...doesn't value it & "Because I don't really like them" \\
\hline No Answer & 1 & No answer & $\mathrm{N} / \mathrm{A}$ \\
\hline
\end{tabular}

\section{DISCUSSION}

Intrinsic traits, personal histories, and needs of the visitors are important variables that influence what goes on in free-choice institutions, including zoos (Grack Nelson \& Cohn, 2015; Falk \& Dierking,
2013). This paper explored some intrinsic traits (knowledge, interest, and value) as well as relationships found between these constructs. Next, I connect these findings to existing work and discuss what I believe these new understandings mean for 
Table 5. Youth grouped by high $(\mathrm{H})$ and low $(\mathrm{L})$ knowledge, interest, and value $(\mathrm{N}=37)$

\begin{tabular}{lllll}
\hline Knowledge & Interest & Value & $\begin{array}{l}\text { Number of } \\
\text { Participants }\end{array}$ & Mean Age \\
\hline $\mathrm{H}$ & $\mathrm{H}$ & $\mathrm{H}$ & 6 & 10.8 \\
$\mathrm{H}$ & $\mathrm{H}$ & $\mathrm{L}$ & 2 & 12.0 \\
$\mathrm{H}$ & $\mathrm{L}$ & $\mathrm{H}$ & 3 & 9.3 \\
$\mathrm{H}$ & $\mathrm{L}$ & $\mathrm{L}$ & 2 & 10.0 \\
$\mathrm{~L}$ & $\mathrm{H}$ & $\mathrm{H}$ & 12 & 8.7 \\
$\mathrm{~L}$ & $\mathrm{~L}$ & $\mathrm{H}$ & 7 & 9.3 \\
$\mathrm{~L}$ & $\mathrm{~L}$ & $\mathrm{~L}$ & 5 & 11.6 \\
\end{tabular}

wildlife education centers and the field of free-choice education.

\section{Knowledge}

In the knowledge assessment, children had the freedom to express their knowledge in ways consistent to their own meanings about animal topics. The most common categories of vocabulary used by youth were ecological and physiological needs, traits, and activities of animals. This is similar to the findings by Myers et al. (2004) who found that physiological needs (air, water, food) were grasped first at an early age. Concrete understandings of ecological needs were also common in their study, particular among youth between 8-10 years old, which aligns with the age range in my study (Myers et al., 2004). It was surprising that no youth mentioned conservation knowledge in these interviews since one of the zoo's focuses is conservation and Myers et al. (2004) also found that a few youth mentioned conservation needs of animals in their interviews about animal needs. However, studies indicate that ethical and conservation mindsets develop later in adolescence (Myers et al., 2004; Tunnicliffe, 1996) so it could be that youth in this study had not reached this point yet.

The prevalence of ecologicaltype responses in this study might also be attributed to what the youth might be learning at school. According to Ohio standards (Ohio Department of Education, 2011), ecosystems is a topic covered in $5^{\text {th }}$ grade which is around the age of youth in this study. Kentucky and Indiana (nearby states where visitors may live) also cover ecosystems in $5^{\text {th }}$ and $6^{\text {th }}$ grade. Needs of living things are taught in prior grades. A few youth even mentioned that they were doing projects regarding animals and their habitats during the visit and during their interviews.

Children also varied in their scores for mastery. Similar to Palmquist \& Crowley (2007) who studied youth knowledge about dinosaurs, I used accuracy and sophistication of responses as a measure of mastery. It is not surprising that older children received higher scores for mastery. This is consistent with Myers et al. (2004) who found that advanced ecological knowledge develops with age. Palmquist and Crowley found sex differences where boys made up a higher percentage of the youth labeled as experts. Gender differences were not significant in this study, but boys had slightly higher mastery scores and composite scores. The lack of significant difference may be because animals are generally considered a less gendered interest compared to dinosaurs.

I expected more children to display more expertise about animals by referencing specific or unusual facts in their interviews. This is because I predicted that zoo visitors would have higher than average knowledge about animals. However, this was not the case. Responses like "They cough up pellets (bones and fur of animals)... the largest owl is the Great Grey Owl and the smallest is the Pygmy Owl" (Boone, 11) were rare. More common were statements like, "they eat grass and hay" (Claire, 14) that were much simpler in their display of knowledge. This may be due to the age of participants since it was found that older youth tended to mention more advanced or complex facts than younger youth. This is not surprising since older youth likely are better able to remember these complex facts and have had more experiences to develop a more advanced knowledge.

\section{Interest}

Unlike knowledge, mean interest scores were more skewed toward the upper end of the scale. This is not surprising since the decision to visit a zoo, versus another activity, indicates some sort of interest in animals. Renninger \& Hidi (2011) predict that those with an interest in a particular subject have a higher intrinsic motivation to engage with an interest. Attending the zoo may be a result of existing 
interest in animals, or it may provide a hook or outlet for developing interest.

As predicted by Lent et al. (1994), children's career interests aligned with youth's mean interest in animals. Those with the highest interest in animals had an interest in pursuing a career involving animals such as a zookeeper or veterinarian. Animal-related careers were the most common career choice mentioned by participants with over $46 \%$ of participants wanting a career in this area. This also indicates that a large percentage youth that visit zoos have a high interest in animals since the percentage of youth's career interests among the broader population of children is more varied among many different types of careers (Sax, 1994).

The high interest among youth for animal related careers provides evidence for increasing careerfocused programming at zoos. Many zoos host camps or programs for youth interested in pursuing a career in animal science, but most of these focus on jobshadowing zookeepers. Perhaps zoos could explore means of connecting youth with other STEM-related careers that focus on animals such as biologists, environmental engineers/regulators, and education as a way of increasing interest in and knowledge about these career options. We need to cultivate a future generation of animal advocates to reach broad conservation goals.

\section{Value}

Mean value scores were also skewed toward the high end, even more so than interest. Again, this may be due to self-selection that zoo visitors tend to have higher regard for animals. Youth may also have been under pressure to "perform" in this section of the survey since not having value for animals is generally seen as a negative thing. Values are also complex and multi-faceted and so difficult to measure in the short time of this study.

When asked why animals are important, the most common answer was ecologistic. Youth in this category see value in animals based on the animal's role in the ecosystem. As discussed above, this is consistent with developmental studies that found ecological conceptions of animal needs generally develop before advanced moral values and concerns for wellbeing (Myers et al., 2004). According to Kellert (1985), affective and emotional relationships to animals occur first (6-9 years) followed by an increase in cognitive knowledge of animals (10-13). Ethical concern generally occurs later around 13-16 years old. Thus, my participants generally fell into this cognitive concern period. Similar to interest, it is also possible that this particular response for value was popular because this age group is gaining cognitive knowledge about ecosystems in school as discussed above. For example, one of the standards for $5^{\text {th }}$ grade is, "organisms have symbiotic relationships in which individuals of one species are dependent upon individuals of another species for survival" (Ohio Department of Education, 2011). Many participants mentioned value for animals "because they play a vital role in ecosystems" (Kate, 12).

Many participants also mentioned finding value in animals because of their endangered or uncommon status. This was not one of the value categories listed by Kellert \& Berry (1987) but may be related to the construct of "conservation caring" as outlined by Skibins \& Powell (2013). The authors define this trait as awareness of the consequences of human action and importance of saving species. This emergent category may be primed by the common knowledge that zoos advocate for conservation of endangered species. "Endangered species" is also a vocabulary term learned around $5^{\text {th }}$ grade (Ohio Department of Education, 2011). It is encouraging that many youth mentioned their concern for the rarity of species and used the word "endangered" even if the word conservation was not used. Concern for endangered species matches the goals of zoos and most zoo professionals seek to capitalize on this concern to cultivate pro-environmental behaviors.

Finally, almost all children chose a mammal as their favorite animal in the knowledge activity, particularly tigers, elephants, and lions. This aligns with studies indicating people having a stronger affiliation towards charismatic mega fauna and those perceived as being entertaining or cute (Carr, 2016). Skibins \& Powell (2013) assert that conservation caring and value are closely linked to preferences for species so youths' favorite animal has implications for value development. Zoos already place much of their advertising and social media focus on these sorts of large charismatic animals. More research is needed to know if these sorts of campaigns are effective for the development of values among youth.

\section{Relationship between Traits}

Mean interest and value scores were related to each other but not to knowledge scores. This may be due to the similarity in the survey questions used to measure these constructs. Youth answered questions about interest and value in a series of multiple-choice questions using the same scale and answered at the same time. Thus, youth's answers to one part of the survey were likely influenced by their answers on the other part. Conversely, knowledge was assessed in a very different manner with a drawing activity so this could account for the lack of relationship between knowledge and the other two traits. However, the relationship between interest and value is consistent 
with Uitto \& Saloranta (2010) who asserted that value orientations might affect interest and engagement and Hidi \& Renninger (2006) suggest interest results in more stored value for the object of interest.

At first, it might be surprising that knowledge was not related to the other variables since many studies indicate that interest predicts knowledge seeking behaviors. However, age may influence these results. When grouped as high vs low knowledge/interest/value, low knowledge-high interest/value participants were younger on average. This aligns with theories by Hidi \& Renninger (2006) that interest may preclude knowledge-seeking activities. Similarly, a study by Falk \& Adelman (2003) found that knowledge gains during a single visit were only significant for those with high prior interest indicating that interest is an important prerequisite for knowledge development. These patterns are speculative since the study was not designed to measure developmental trends and the sample size among the groups was small, but this represents an avenue for future study.

Although the youths self-reported affective traits did not correlate with their knowledge score, parents of children with higher knowledge scores rated their child as having a higher interest in a career in animals. This is similar to a finding by Palmquist and Crowley (2007) who found that parents of so-called "expert" children rated their child as having high interest in dinosaurs. This led parents to provide more opportunities for their expert children to engage and learn about dinosaurs such as buying dinosaur related books and toys.

In sum, the conceptual model of learning provides a framework for future research and study into the three traits described in this paper. At the time of this study, most school-aged children framed their knowledge of animals from the concepts they were learning in school such as the basic needs of animals or their habitats. The children who visited the zoo seemed to have a high level of interest in animals, perhaps because of their frequent visits to zoos in the past with their families. Parents may also cultivate an interest in animals if they perceive their child has advanced knowledge about animals. Even children's value for wildlife seemed to be shaped by external factors such as school curriculum or the types of animals frequently seen in the media. While the measurements of intrinsic traits outlined in this study may reference only one point in a child's life, these measurements are important for tracking future change over many years. These changes may be the result of purposeful interventions by informal learning institutions or simply from incidental experiences. Future research will need to be done to dive deeper into the lifelong effects on knowledge, interest, and value.

\section{Interest Statement}

The author declares there is no conflict of interest.

\section{REFERENCES}

Allen, S. (2002). Looking for learning in visitor talk: A methodological exploration. Learning Conversations In Museums. G. Leinhardt, K. Crowley and K. Knutson. Mahwah, Lawrence Erlbaum Associates: 259-303.

Ash, D. (2003). Dialogic inquiry in life science conversations of family groups in a museum. Journal of Research in Science Teaching, 40(2). 138162.

https://citeseerx.ist.psu.edu/viewdoc/download?d oi=10.1.1.476.3346\&rep=rep1\&type =pdf

Bamberg, S., \& Moser, G. (2007). Twenty years after Hines, Hungerford, and Tomera: A new metaanalysis of psycho-social determinants of proenvironmental behavior. Journal of Environmental Psychology, 27, 14-25.

https://www.sciencedirect.com/science/article/ab s/pii/S0272494406000909

Barriault, C., \& Pearson, D. (2010). Assessing exhibits for learning in science centers: A practical tool. Visitor Studies, 13(1). 90-106.

https://www.researchgate.net/publication/233338 902_Assessing_Exhibits_for_Learning_in_Science_Ce nters_A_Practical_Tool

Carr, N. (2016). An analysis of zoo visitors' favourite and least favourite animals. Tourism Management Perspectives, 20. 70-76.

https://www.sciencedirect.com/science/article/ab s/pii/S2211973616300708\#: :text=The\%20result s\%20show $\% 20$ that $\% 20$ mammals,see $\% 20$ tend $\% 20$ not $\% 20$ to $\% 20$ appeal.

Christidou, D. (2013). Bringing meaning into making: How do visitors tag an exhibit as social when visiting a museum. The International Journal of the Inclusive Museum, 6(1). 73-85.

https://www.researchgate.net/publication/259641 897_Bringing_Meaning_into_Making_How_Do_Visito rs_Tag_an_Exhibit_as_Social_when_Visiting_a_Museu $\mathrm{m}$

Chung, J., Cannady, M. A., Schunn, C., Dorph, R., \& Bathgate, M., (2016) Measures Technical Brief: Fascination in Science. Retrieved from: http://www.activationlab.org/wpcontent/uploads/2016/02/Fascination-Report-3.220160331.pdf

Crowley, K., Callanan, M.A., Jipson, J.L., Galco, J., Topping, K., \& Shrager, J. (2000). Shared scientific thinking in everyday parent-child activity. Science Education, 85(6). 712-732. 
https://onlinelibrary.wiley.com/doi/abs/10.1002/ sce.1035

Falk, J. (2006). An identity-centered approach to understanding museum learning. Curator, 49(2). 151-166. https://onlinelibrary.wiley.com/doi/abs/10.1111/j .2151-6952.2006.tb00209.x

Falk, J. H., \& Adelman, L. M. (2003). Investigating the impact of prior knowledge and interest on aquarium visitor learning. Journal of Research in Science Teaching, 40(2). 163-176. https://onlinelibrary.wiley.com/doi/abs/10.1002/t ea. 10070

Falk, J. H., \& Dierking, L. D. (2013). The Museum Experience Revisited. Walnut Creek, CA: Left Coast Press Inc.

Falk, J. H., Heimlich, J. E., \& Foutz, S. (2009). Free-choice learning and the environment. Lanham, MD: AltaMira Press.

Falk, J., Moussouri, T., \& Coulson, D. (1998). The effect of visitors' agendas on museum learning. Curator, 41(2), 107-120. https://onlinelibrary.wiley.com/doi/abs/10.1111/j .2151-6952.1998.tb00822.x

Geerdts, M. S., Van de Walle, G. A., \& LoBue, V. (2015). Parent-child conservations about animals in informal learning environments. Visitor Studies, 18(1). 39-63.

https://www.tandfonline.com/doi/abs/10.1080/1 0645578.2015 .1016366

Grack Nelson, A., \& Cohn, S. (2015). Data collection methods for evaluating museum programs and exhibitions. Journal of Museum Education, 40(1). 27-36.

https://www.tandfonline.com/doi/abs/10.1080/1 0598650.2015.11510830

Hidi, S., \& Renninger, K. A. (2006). The four-phase model of interest development. Educational Psychologist, 41(2). 111-127. https://www.tandfonline.com/doi/abs/10.1207/s1 5326985ep4102_4

Jensen, E. (2013). Evaluating children's conservation biology learning at the zoo. Conservation Biology, 28 (4). 1004-1011.

https://conbio.onlinelibrary.wiley.com/doi/abs/10 $.1111 /$ cobi.12263

Johnston, R. J. (1998). Exogenous factors and visitor behavior: A regression analysis of exhibit viewing time. Environment and Behavior, 30. 332-347. https://journals.sagepub.com/doi/abs/10.1177/00 1391659803000304

Kellert, S. R. (1985). Attitudes toward animals: Agerelated development among children. The Journal of Environmental Education, 16(3). 29-39.

Kellert, S. R., \& Berry, J. K. (1987). Attitudes, knowledge, and behaviors toward wildlife as affected by gender. Wildlife Society Bulletin, 15. 363-371. https://www.jstor.org/stable/3782542
Kidd, A.H., \& Kidd, R.M. (1996). Developmental factors leading to positive attitudes toward wildlife and conservation. Applied Animal Behaviour Science, 47. 119-125.

https://www.sciencedirect.com/science/article/ab s/pii/0168159195010157

Kimble, G. (2014). Children learning about biodiversity at an environment centre, a museum and at live animal shows. Studies in Educational Evaluation, 41. 48-57.

https://www.sciencedirect.com/science/article/ab s/pii/S0191491X13000370

Kisiel, J., Rowe, S., Vartabedian, M.A., \& Kopczak, C. (2012). Evidence for family engagement in scientific reasoning at interactive animal exhibits. Science Education, 96(6). 1047-1070. https://onlinelibrary.wiley.com/doi/abs/10.1002/ sce. 21036

Lent, R. W., Brown, S. D., \& Gail, H. (1994). Toward a unifying social cognitive theory of career and academic interest, choice, and performance. Journal of Vocational Behavior, 45(1). 79-122.

https://www.sciencedirect.com/science/article/ab s/pii/S000187918471027X

Moss, A., \& Esson, M. (2010). Visitor interest in zoo animals and the implications for collection planning and zoo education programmes. Zoo Biology, 29. 715-731.

https://pubmed.ncbi.nlm.nih.gov/20333734/

Myers, O. E. Jr., Saunders, C. D., \& Garrett, E. (2004).

What do children think animals need?

Developmental trends. Environmental Education Research, 10(4). 545-562.

https://www.tandfonline.com/doi/abs/10.1080/1 $350462042000291056 ? \mathrm{src}=$ recsys $\&$ journalCode $=c$ eer20

Ohio Department of Education (2011). Ohio's new learning standards: science standards. Retrieved from:

http://education.ohio.gov/getattachment/Topics/0 hios-Learning-

Standards/Science/ScienceStandards.pdf.aspx

Palmquist, S., \& Crowley, K. (2007). From teachers to testers: How parents talk to novice and expert children in a natural history museum. Science Education, 91(5). 783-804.

https://onlinelibrary.wiley.com/doi/abs/10.1002/ sce.20215

Perry, D. L. (2012). What makes learning fun: Principles for the design of intrinsically motivating museum exhibits. Lanham, Maryland: AltaMira Press.

Renninger, K. A., \& Hidi, S. (2011). Revisiting the conceptualization, measurement, and generation of interest. Educational Psychologist, 40(3). 168-184. https://www.tandfonline.com/doi/abs/10.1080/0 0461520.2011 .587723

Sax, L. J. (1994). Retaining tomorrow's scientists: Exploring the factors that keep male and female 
college students interested in science careers.

Journal of Women and Minorities in Science and Engineering, 1(1), 45-61.

https://escholarship.org/uc/item/8076408w

Skibins, J. C., \& Powell, R. B. (2013). Conservation caring: Measuring the influence of zoo visitors' connection to wildlife on pro-conservation behaviors. Zoo Biology, 32, 528-540.

https://www.researchgate.net/publication/251235 431_Conservation_Caring_Measuring_the_Influence_ of_Zoo_Visitors'_Connection_to_Wildlife_on_ProConservation_Behaviors

Tunnicliffe, S. D. (1996). Conversations within primary school parties visiting animal specimens in a museum and zoo. Journal of Biological Education, 30(2). 130.

https://www.tandfonline.com/doi/abs/10.1080/0 0219266.1996 .9655491

Uitto, A., \& Salorenta, S. (2010). The relationship between secondary school students' environmental and human values, attitudes, interests and motivations. Procedia Social and Behavioral Sciences, 9, 1866-1872.

https://www.sciencedirect.com/science/article/pii /S1877042810025206

Wagoner, B., \& Jenson, E. (2010). Science learning at the zoo: Evaluating children's developing understanding of animals and their habitats. Psychology \& Society, 3(1). 65-76.

https://www.researchgate.net/publication/320192 515_Science_Learning_at_the_Zoo_Evaluating_Childr en's_Developing_Understanding_of_Animals_and_th eir_Habitats 